\title{
Fractionation of potentially toxic elements in urban soils from five European cities by means of a harmonised sequential extraction procedure
}

Christine. M. Davidson ${ }^{\mathrm{a}^{*}}$, Graham J. Urquhart ${ }^{\mathrm{a}}$, Franco Ajmone-Marsan ${ }^{\mathrm{f}}$, Mattia Biasioli ${ }^{\mathrm{f}}$, Armando da Costa Duarte ${ }^{\mathrm{b}}$, Encarnación Díaz-Barrientos ${ }^{\mathrm{e}}$, Helena Grčman $^{\mathrm{c}}$, Ian Hossack ${ }^{\mathrm{d}}$, Andrew S. Hursthouse ${ }^{\mathrm{d}}$, Luis Madrid ${ }^{\mathrm{e}}$, Sonia Rodrigues ${ }^{\mathrm{b}}$, Marko Zupan ${ }^{\mathrm{c}}$.

${ }^{a}$ Department of Pure \& Applied Chemistry, University of Strathclyde, 295 Cathedral St, Glasgow G1 1XL, UK.

${ }^{b}$ Departamento de Química, Universidade de Aveiro 3810-193 Aveiro, Portugal.

${ }^{c}$ Univerza v Ljubljani, Biotehniska fakulteta, 1000 Ljubljana, Slovenia.

d School of Engineering \& Science, University of Paisley, High Street, Paisley, PA1 2BE, UK.

${ }^{\mathrm{e}}$ Instituto de Recursos Naturales y Agrobiología de Sevilla (CSIC), Apartado 1052, 41080, Sevilla, Spain.

${ }_{\mathrm{f}}^{\mathrm{f}}$ DI.VA.P.R.A., Chimica Agraria, Università di Torino, Via Leonardo da Vinci, 44, 10095 Grugliasco, Torino, Italy

* corresponding author: c.m.davidson@strath.ac.uk

\section{Abstract}

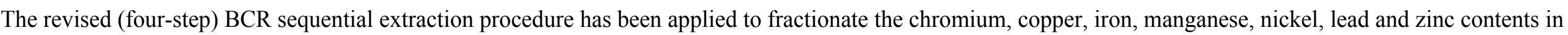
urban soil samples from public-access areas in five European cities. A preliminary inter-laboratory comparison was conducted and showed that data obtained by

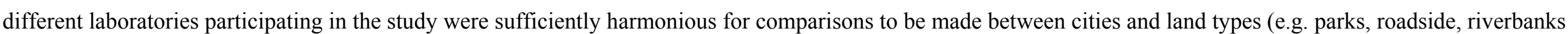

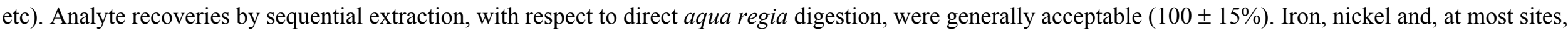

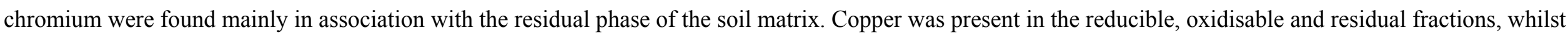

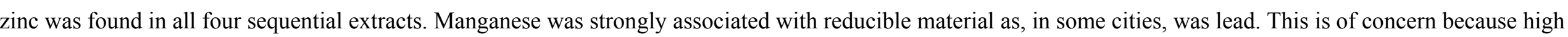

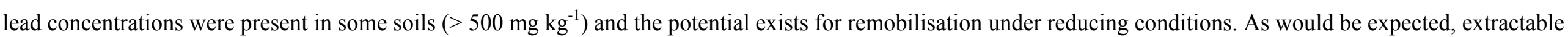
metal contents were generally highest in older, more heavily industrialised cities. Copper, lead and zinc showed marked (and often correlated) variations in

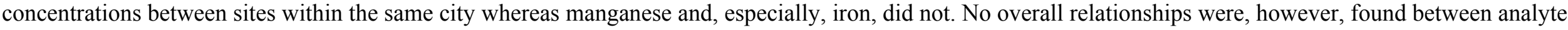
concentrations and land use, nor between analyte partitioning and land use.

\section{Keywords}

Potentially toxic elements, potentially toxic metals, urban soil, sequential extraction 


\section{Introduction}

Urban soils are less studied than agricultural soil but are an increasing focus of attention [1]. Soils in urban environments are often highly variable in composition, due to a wide variety of human influences, and typically contain higher loadings of contaminants than those from rural settings due to the higher density of anthropogenic activity in urbanised areas. Only a small fraction of urban soil is used for food production (domestic gardens, allotments etc). However, since the majority of the population in developed countries live or work in urban areas, this is the type of soil with which most people have direct contact through, for example, use of publicaccess recreational areas such as parks and ornamental gardens.

Fractionation of the trace element content of environmental solids by application of a series of extractants provides (operationally-defined) information on reservoirs of metal that are likely to respond in different ways to changes in ambient conditions such as $\mathrm{pH}$ or redox potential [2]. The approach also gives an indication of the mineralogical phase(s) to which analytes are bound, although this information is limited by phenomena such as analyte re-adsorption, incomplete extraction, and nonspecificity of reagents for "target" phases. The large variety of sequential extraction procedures now available was highlighted recently [3]. However, one of the most widely applied protocols remains that developed [4] and later revised [5] under the auspices of the European Commission, Community Bureau of Reference (BCR). Although originally intended for application to sediments, the BCR scheme has been applied successfully in the study of a wide variety of other substrates, including several different types of soils. It has the advantages of simplicity (only 4 steps are involved) and availability of certified reference materials (e.g. BCR CRM 701) for method validation.

Concentrations of potentially toxic elements (PTE) in urban soils have been reported for cities in diverse parts of the world. These include Aberdeen (UK) [6], Basel (Switzerland) [7], Bombay (India) [8], Damascus (Syria) [9], East St Louis (USA) [10], Falun (Sweden) [11], Gaborone (Botswana) [12], Glebe (Australia) [13], Hong Kong (China) [14], Honolulu (USA) [15], Jakobstad (Finland) [16], Central Jordan [17], Kyoto (Japan) [18], Madrid (Spain) [19], Montreal (Canada) [20], Naples (Italy) [21], New Orleans (USA) [22], Palermo (Italy) [23], Poznan (Poland) [24] and Sevilla (Spain) [25]. There has also been interest in the application of sequential extraction to urban soils, from the early work of Gibson and Farmer in Glasgow (UK) [26] to more recent studies in Bangkok (Thailand) [27], Danang-Hoian (Vietnam) [28], Hangzhou [29], Nanjing [30], Hong Kong [31, 32] (all in China) and Naples (Italy) [33]. However, a major limitation of previous research in the field 
is the use of different sequential extraction protocols by different workers. Application of different reagents, extraction conditions, and number of extraction steps (between three and seven) makes it extremely difficult to compare results obtained in different cities.

This paper describes the application of a harmonised sequential extraction procedure, the revised BCR protocol [5], to fractionate the chromium, copper, iron, manganese, nickel, lead and zinc content in urban soils from public-access areas in five European cities, together with results of a preliminary exercise conducted to assess inter-laboratory comparability. The work was conducted as part of the EU URBSOIL project, the overall aims of which were to assess the role of soil as a source, or sink, for pollutants in the urban environment, and to promote the integration of soil quality information into the urban planning process.

\section{Experimental}

Sampling

Urban soil samples were collected, by means of a spade or trowel, from different types of public-access space (ornamental gardens (OG), parks and open spaces (PO), riverbanks (RB), roadsides (RD), school playing fields (SC) and urban agricultural land (AG)). Soils from five European cities were studied: Aveiro, Portugal (AVE); Glasgow, UK (GLA); Ljubljana, Slovenia (LJU); Sevilla, Spain (SEV) and Torino, Italy (TOR). Samples from twenty sites in each city, drawn from a larger set, were selected for sequential extraction. Sites were selected to give broad geographical coverage and to reflect the most important land use types within each city. A harmonised sampling regime was applied by all partners, although minor modifications were sometimes necessary because of the presence of paved pathways or other obstacles. Soil was collected from five individual sampling points at each site, to a depth of $10 \mathrm{~cm}$, and bulked to give a composite sample. For PO sites, the sampling points were defined as the centre and corners of a square with a diagonal of length $20 \mathrm{~m}$. For RD and RB sites the points were at $10 \mathrm{~m}$ intervals along a $40 \mathrm{~m}$ transect parallel to the road or river. OG, SC and AG sites were sampled similarly to PO, where feasible, but frequent alterations to the sampling pattern were necessary to take account of the locations and dimensions of the accessible soil areas. Soils were air dried and sieved to $<2 \mathrm{~mm}$ particle size in the city where they were collected before being re-distributed amongst project partners for analysis. Sequential extraction and measurement of PTE was carried out in three cities: soils from Aveiro, Sevilla and Torino were extracted and analysed in Sevilla; Ljubljana soils were extracted and analysed in Ljubljana; Glasgow soils were extracted at the University of Strathclyde then the extracts transported to the University of Paisley for analysis. 
Apparatus and Reagents

The equipment and reagents used in extraction and determination of chromium, copper, iron, manganese, nickel, lead and zinc are summarised in Table 1.

Quantification of cadmium was also attempted but levels proved to be too close to procedural detection limits (typically $0.5 \mathrm{mg} \mathrm{kg}^{-1}$ for this element) in many of the extracts, for reliable results to be obtained. All plastic and glassware was acid-soaked overnight $\left(5 \% \mathrm{HNO}_{3}\right)$ and rinsed with distilled water before use.

\section{Procedures}

Pseudo-total metal contents were determined by digesting air-dried urban soil samples in hot aqua regia $\left(3 \mathrm{HCl}: 1 \mathrm{HNO}_{3}\right)$ as described in Table 1 .

Sequential extraction was carried out according to the revised BCR protocol. The procedure is summarised below and described in full in reference [5].

Step 1 (water / acid soluble and exchangeable fraction): $40 \mathrm{ml}$ of $0.11 \mathrm{~mol}^{-1}$ acetic acid was added to $1 \mathrm{~g}$ soil and shaken for $16 \mathrm{~h}$ at room temperature. The extract was separated from the solid by centrifugation, decanted into a polyethylene bottle and stored at $4{ }^{\circ} \mathrm{C}$. The residue was washed with distilled water and the washings discarded.

Step 2 (reducible fraction): $\quad 40 \mathrm{ml}$ of $0.5 \mathrm{~mol}^{-1}$ hydroxylammonium chloride (adjusted to $\mathrm{pH} 1.5$ by the addition of a prescribed volume of nitric acid) was added to the residue from step 1 , and the extraction performed as described for step 1.

Step 3 (oxidisable fraction): The residue from step 3 was digested with hydrogen peroxide (for details see [5]), reduced in volume, then $50 \mathrm{ml}$ of $1.0 \mathrm{~mol} \mathrm{l}^{-1}$ ammonium acetate (adjusted to $\mathrm{pH} 2$ with nitric acid) was added and the extraction performed as described for step 1.

Step 4 (residual fraction): $\quad$ The residue from step 3 was slurried in a small volume of aqua regia, transferred (as quantitatively as possible) to a suitable vessel and digested using the same procedure as described for the pseudo-total metal determination. 


\section{Results and Discussion}

Analysis of CRMs

All three laboratories conducting the analysis extracted appropriate certified reference materials, in parallel with extraction of the urban soil samples, to assess the quality of their methodology. Results are presented in Table 2. Agreement between found and certified values was generally acceptable i.e. results were within two standards deviations of the certified concentration in most steps, and within three standard deviations in almost all steps. Exceptions occurred for the measurement of chromium in step 3 by the Glasgow laboratory (in BCR CRM 601); for copper, nickel and lead in step 2, copper in step 3, and nickel in step 4, by workers in Sevilla, and for copper in steps 1-3, lead in steps 2 and 4, and zinc in step 1, in Ljubljana. Some of the discrepancies may be due to underestimation of the uncertainty in the measured values, but there is a suggestion that a portion of the copper certified as being in the acid-exchangeable and reducible fractions of BCR CRM 701 is not being isolated until step 3 .

Inter-laboratory comparison

A set of urban soil secondary reference materials had been prepared by participants in the URBSOIL project for use as internal quality control samples. One of these soils was used to compare the performance of the three laboratories conducting sequential extraction. The purpose was to assess whether minor deviations from the prescribed BCR protocol, such as use of shaking speeds outside the recommended range of $30 \pm 10 \mathrm{rpm}$, would cause discontinuities between results generated in Glasgow, Ljubljana and Sevilla. Such an assessment is an important (but often neglected) preliminary stage of collaborative research projects, necessitated by the availability of different apparatus, and the use of different, preferred, analytical procedures, in different laboratories. The selected soil was from a park close to the centre of Glasgow. It was considered a more suitable basis for the inter-laboratory comparison than available certified reference materials because it is similar in matrix composition (and analyte concentrations) to the samples studied. In contrast, both BCR CRM 601 and BCR CRM 701 are freshwater lake sediments.

Statistical analysis (ANOVA at $95 \% \mathrm{CI}$, except for Fe where a t-test assuming unequal variance was applied) indicated significant between-laboratory variability in the pseudototal metal concentrations reported by the Glasgow, Ljubljana and Sevilla laboratories for the Glasgow urban soil (Table 3). Results differed by up to 25\% for some elements. This may be partly due to the inhomogeneity typical of urban soils. However, it is noticeable that, for many elements, lowest concentrations were those measured in Sevilla and highest were those from Ljubljana, suggesting that the microwave digestion procedures used were of unequal efficiency. 
Despite the variability in pseudototal metal concentrations generally similar PTE fractionation patterns were obtained by the three laboratories (Figure 1). Also, metal recoveries by means of the BCR procedure, $\Sigma$ (steps 1-4), were between 87 and $110 \%$ of corresponding pseudototal values. There were a few exceptions. The Sevilla laboratory appeared to slightly under-extract iron and nickel ( 84 and $81 \%$, recovery, respectively) and the Ljubljana laboratory obtained excess extractable zinc ( $134 \%$ recovery). Inefficient attack on the solid phase, in steps 2 (reducible) and 4 (residual), may explain the poor iron and nickel results, but this is not supported by data obtained for other elements in Sevilla e.g. chromium and lead. The anomalous zinc recovery in Ljubljana arises because concentrations almost equivalent to the pseudototal value were found, in the step 4 extracts, in three of the four replicates analysed (the fourth replicate produced an acceptable recovery of $98 \%$ ). This suggests that gross contamination of some of the residual extracts had occurred - and highlights the necessity to cross-check sequential extraction results with those obtained by direct aqua regia digestion. Recoveries less than equivalent pseudototal values were reported for copper by all three participants. The worst performance for this element was that obtained in Glasgow (recovery $87 \%$ ). This appears to result from underestimation of the copper content in the oxidisable phase. The loss may represent copper associated with low-density, particulate, organic matter, which is difficult to isolate by centrifugation and may be inadvertently discarded with the washings at the end of steps 1 and 2; or loss of copper in the form of water-soluble complexes with dissolved organic matter. However, it is not clear why the effect should be more prevalent in one laboratory than in the others.

Between-laboratory discrepancies of the magnitude reported are typical in work of this nature (see, for example, results of the inter-comparisons conducted during certification of BCR CRM 601 [36]), Overall, there was sufficient similarity between results obtained in the three laboratories for comparisons to be made between analyte partitioning patterns in urban soil samples analysed in different laboratories.

\section{PTE fractionation in urban soil samples}

The fractionation of analytes in 20 urban soils from each of the five cities is shown in Figures 2-8. Results are arranged by analyte, city and land type. Mean recoveries with respect to pseudototal values for each analyte and city were in the range $87-110 \%$, which is considered acceptable given the intrinsic heterogeneity of urban soils. Exceptions occurred for chromium in soils from Aveiro (142\% recovery), copper in Glasgow soils (82\%), iron in samples from Sevilla (77\%) and nickel in soils from both Aveiro (66\%) and Sevilla (70\%). In each case, the effect (under- or over-extraction of a particular analyte relative to direct digestion with aqua regia) was observed for almost all soils from the city. This is probably due, in part, to inter-laboratory differences already seen in the analysis of the inter-comparison sample i.e. 


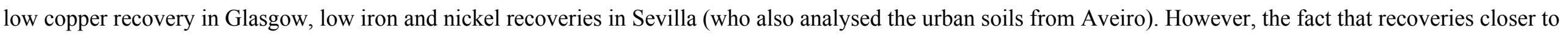

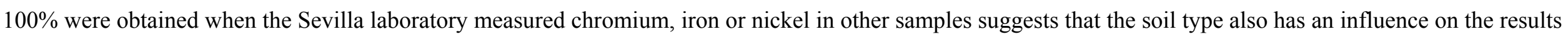
obtained by the BCR extraction.

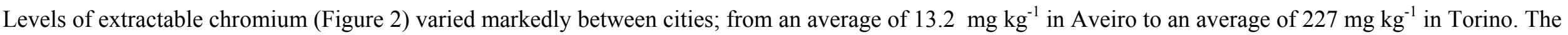

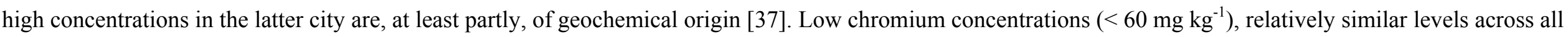

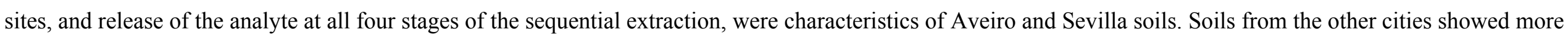

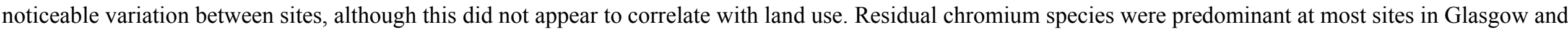

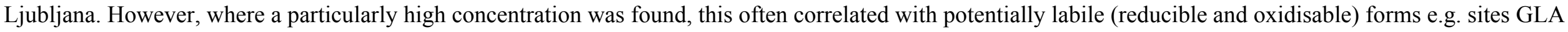
PO.15, GLA PO.32 and LJU PO.15. The south-east of Glasgow is known to be contaminated with chromium because of the disposal of waste by chemical manufacturing industry in the $19^{\text {th }}$ Century [38], and this may explain the high levels at GLA PO.15. However, GLA PO.32 is in a different area of the city and the

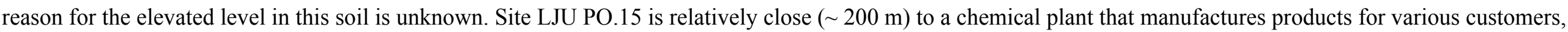

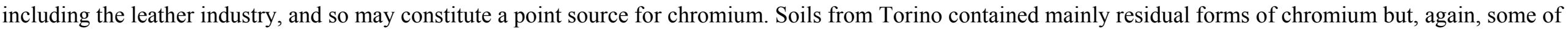
the sites with the highest analyte content also had higher than average contribution from reducible and oxidisable fractions. Higher chromium concentrations were

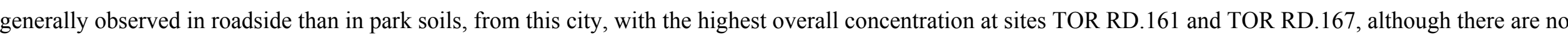
known anthropogenic point sources at these locations.

Aveiro soils again contained the lowest average concentration for copper (Figure 3) with the notable exception of site AVE OG/RD.17, which contained 10x more

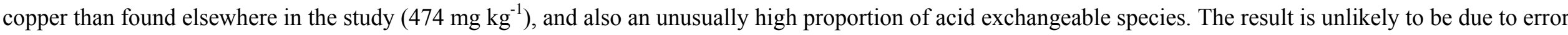

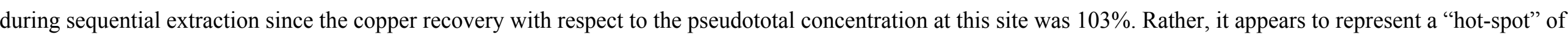

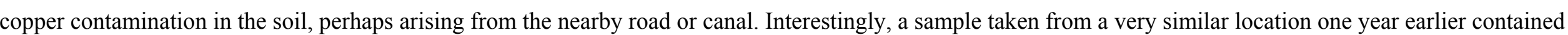

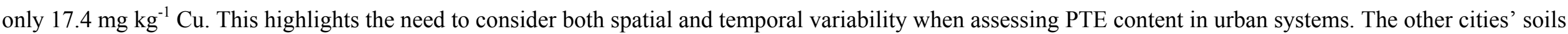

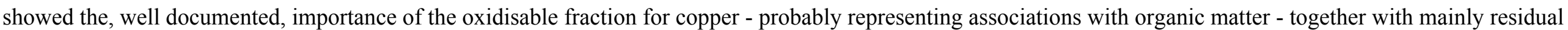
forms in Ljubljana and Sevilla, and reducible and residual forms in Glasgow and Torino. Marked concentration variations were evident in most cities, but no clear 
relationship between copper content and type of land sampled. Recent work in Sevilla [39] has shown that copper, lead and zinc concentrations were slightly lower than average in riverbank samples and noticeably higher in soil from ornamental gardens, but this was based on a larger sample set than the current study.

Extractable concentrations of iron were higher in Glasgow and Torino soils than in soils from Aveiro and Sevilla (Figure 3) but the operational speciation was similarly dominated by residual species (as might be expected for an element whose minerals constitute a major structural components of soil) with small contributions from reducible forms. There was relatively little between-site variation within each city. Similar comments apply to manganese (Figure 5) although, here, the reducible fraction was generally the largest (as expected since manganese oxyhydroxides are a principal target of the hydroxylammonium chloride reagent) and variability between sites was somewhat larger than for iron. Ljubljana and Torino soils were, on average, the richest in extractable manganese (levels of 894 and $812 \mathrm{mg} \mathrm{kg}^{-1}$, respectively), followed by Sevilla $\left(424 \mathrm{mg} \mathrm{kg}^{-1}\right)$ and Glasgow $\left(416 \mathrm{mg} \mathrm{kg}^{-1}\right)$. Lowest concentrations were found in the samples from Aveiro $\left(\mathrm{mean}=97 \mathrm{mg} \mathrm{kg}^{-1}\right)$.

Nickel displayed some similar trends to chromium. Residual forms were dominant in all cities, highest concentrations were found in Torino (due, as for chromium, to the presence of serpentinites in the River Po catchment [37]), and sites TOR RD.161 and TOR RD.167 contained the highest levels of all those included in the study (490 and $824 \mathrm{mg} \mathrm{kg}^{-1}$, respectively). In contrast, no sites from the other cities, except GLA PO.15 and GLA PO.24, contained $>50 \mathrm{mg} \mathrm{kg}^{-1}$ extractable nickel.

Of the elements studied, lead showed the greatest between-site variation in concentration, especially in Sevilla and Torino (see Figure 7). Mean extractable lead concentrations were of a similar magnitude in Glasgow $\left(212 \mathrm{mg} \mathrm{kg}^{-1}\right)$, Sevilla $\left(183 \mathrm{mg} \mathrm{kg}^{-1}\right)$ and Torino $\left(221 \mathrm{mg} \mathrm{kg}^{-1}\right)$ but contamination appeared to be more widespread in Glasgow, whereas the two other cities' soils were generally less polluted, except for specific sites with high lead levels (> 500 mg kg-1 $)$. In terms of extraction patterns, lead was present mainly in reducible forms in Aveiro, Glasgow and Torino (in contrast to previous work involving the BCR extraction in Naples [33] which reported 77 \% residual lead) but in oxidisable and residual forms in Sevilla. Results from Ljubljana were unusual in that some sites, within the same landuse category, were dominated by reducible lead species and some by oxidisable lead species. This effect may be related to carbonate content. Ljubljana soils containing $>30 \% \mathrm{CaCO}_{3}$ (LJU.RD.02, LJU.RD.04, LJU.RD.05 and LJU.SC.12) released the most lead in step 3 whilst those with $<15 \%$ CaCO 3 (except LJU.SC.08) released most lead in step 2. Soils with between 15 and $30 \%$ showed variable behaviour. 


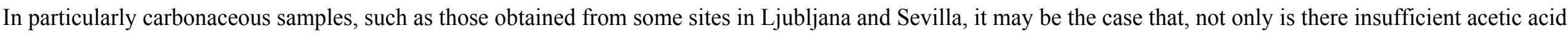
in step 1 of the extraction to dissolve all the $\mathrm{CaCO}_{3}$ present, but also the residual carbonate is able to significantly raise the pH of the reagent used in step 2 . This

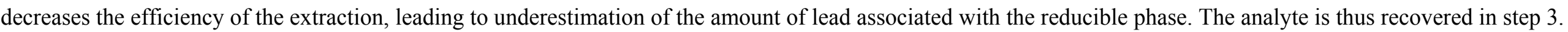
The effect is clearest for lead but can be observed for other elements e.g. copper. This finding highlights the operational nature of sequential extraction and demonstrates clearly that such procedure cannot be relied upon to provide information on specific, mineralogical phase associations of PTEs.

Zinc was found in association with all four operationally-defined fractions in most soils (Figure 8) although the proportions varied between cities and sites. It is noticeable that many of the sites containing the highest extractable zinc levels were also the richest in copper and lead (GLA PO.15 and PO24; SEV OG.3, PO.25,

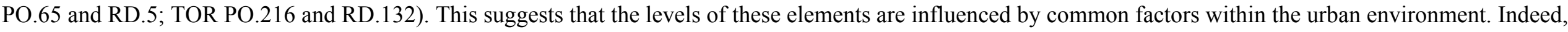

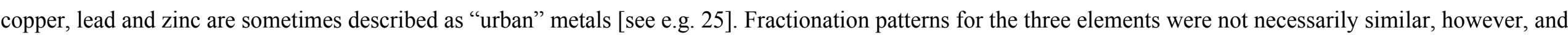
differences were evident between analytes (compare copper, lead and zinc distributions in soil TOR PO.216) and between cities.

\section{Conclusions}

Application of a harmonised sequential extraction procedure has allowed comparison of the operationally defined partitioning of seven PTEs in urban soil samples

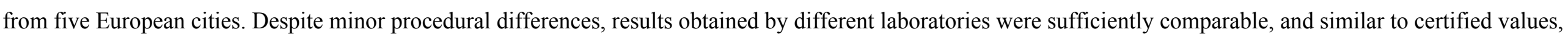
to allow measurements made in different countries to be included in the study.

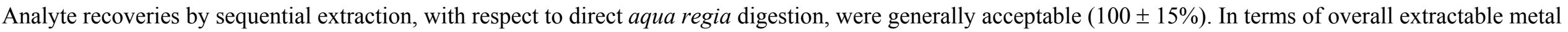
contents (sum of steps of sequential extraction) soils from Glasgow and Torino were generally more highly contaminated than those from Ljubljana and Sevilla. Lowest PTE concentrations were found in Aveiro soils. This is as expected i.e. the oldest cities, with historical legacies of heavy manufacturing industry, have the highest concentrations of potentially toxic elements in soil. 
Urban metals (copper, lead and zinc) showed marked variations in concentrations between sites within the same city, with the highest values for all three elements often found together in the same samples. Some relations were also evident between concentrations of chromium and nickel, especially in Torino where levels were highest. In contrast, elements more likely to originate mainly from geochemical sources, such as iron, showed low variability in concentration across each city.

Iron, nickel and, at most sites, chromium were found mainly in association with the residual phase of the soil matrix. Copper was mainly in reducible, oxidisable and residual forms, whilst zinc was found in all four sequential extracts. Manganese, together with lead in Aveiro, Glasgow and Torino, was mainly associated with reducible material. This is of concern because lead concentrations at some sites are high and the potential exists for mobilisation under reducing conditions such as could result, for example, from water-logging. In contrast, lead in soils from Sevilla (and in some samples from Ljubljana) showed an apparent association with the oxidisable matrix component(s), although this may be partly an artefact caused by the differing carbonate content of the soil matrix.

No clear relationships were found between analyte concentrations and land use, nor between analyte partitioning and land use.

\section{Acknowledgements}

The URBSOIL project was supported by the EU FP5, Energy, Environment and Sustainable Development Program, under contract EVK4-CT-2001-00053. 


\section{References}

1. P Bullock and P J Gregory (Eds.), Soils in the Urban Environment, Blackwell, Oxford,

1991.

2. A M Ure and C M Davidson (Eds.), Chemical Speciation in the Environment (2 ${ }^{\text {nd }}$ Edn), Blackwell, Oxford, 2002.

3. A V Filgueiras, I Lavilla, C Bendicho, J. Environ. Monit., 4 (2002) 823.

4. A M Ure, Ph Quevauviller, H Muntau, B Griepink, Int. J. Environ. Anal. Chem., 51 (1993) 135.

5. G Rauret, J F Lopez-Sanchez, A Sahuquillo, R Rubio, C Davidson, A Ure, Ph Quevauviller, J. Environ. Monit., 1 (1999) 57.

6. $\quad$ E Paterson, M Sanka, L Clark, Appl. Geochem., 11 (1996) 129.

7. M Niederer, A Maschka-Selig, C Hohl, Environ. Sci. Pollut. Res., 2 (1995) 83.

8. D S Ratha, B K Sahu, Environ. Geol., 22 (1993) 276.

9. A Moller, H W Muller, A Abdullah, G Abdelgawad, J Utermann, Geoderma, 124 (2005) 63.

10. M D Kaminski, S Landsberger, J. Air Waste Manage. Assoc., 50 (2000) 1667.

11. Z Z X Lin, K Harsbo, M Ahlgren, U Qvarfort, Sci. Total Environ., 209 (1998) 47.

12. M Zhai, H A B Kampunzu, M P Modisi, O Totolo, Environ. Geol., 45 (2003) 171.

13. J A Markus, A B McBratney, Aust. J. Soil Res., 34 (1996) 453.

14. X D Li, S L Lee, S C Wong, W Z Shi, L Thornton, Environ. Pollut., 129 (2004) 113.

15. R A Sutherland, C A Tolosa, Water Air Soil Pollut., 127 (2001) 315.

16. P Peltola, M Astrom, Environ. Geochem. Health, 25 (2003) 397.

17. K M Banat, F M Howari, A A Al-Hamad, Environ. Res., 97 (2005) 258.

18. K Katahira, M Yoneda, A Morisawa, Environ. Technol., 21 (2000) 505.

19. E De Miguel, M J de Grado, L F Llamas, A Martin-Dorado, L F Mazadiego, Sci. Total Environ., 215 (1998) 113.

20. Y Ge, P Murray, W H Hendershot, Environ. Pollu., 107 (2000) 137.

21. M Angelone, G Armiento, D Cinti, R Somma, A Trocciola, Fresen. Environ. Bull., 11 (2002) 432.

22. H W Mielke, G Wang, C R Gonzales, B Le, V N Quach, P W Mielke, Sci. Total Environ., 281 (2001) 217. 
23. D S Manta, M Angelone, A Bellanca, R Neri, M Sprovieri, Sci. Total Environ., 300 (2002), 229.

24. W Grzebisz, L Ciesla, J Komisarek, J Potarzycki, Pol. J. Environ. Stud., 11 (2002) 493.

25. L Madrid, E Diaz-Barrientos, R Reinoso, F Madrid, Eur. J. Soil Sci., 55 (2004) 209.

26. M J Gibson and J G Farmer, Environ. Pollut. B - Chem. Phys., 11 (1986) 117.

27. W Wilcke, S Muller, N Kanchanakool, W Zech, Geoderma, 86 (1998) 211.

28. H T T Thuy, H J Tobschall, P V An, Environ. Geol., 39 (2000) 603.

29. M K Zhang, Z V Ke, Pedosphere, 14 (2004) 177.

30. Y Lu, Z T Gong, G L Zhang, W Burghardt, Geoderma, 115 (2003) 101.

31. C S C Wong, X D Li, Sci. Total Environ., 319 (2004) 185.

32. X D Li, C S Poon, P S Lui, Appl. Geochem., 16 (2001) 1361.

33. M Imperato, P Adamo, D Naimo, M Arienzo, D Stanzione, P Violante, Environ. Pollut., 124 (2003) 247.

34. Report EUR 19502 EN, G Rauret, J F Lopez-Sanchez, A Sahuquillo, H Muntau and Ph Quevauviller, European Commission, Brussels, 2000.

35. Report EUR 19775 EN, G Rauret, J F Lopez-Sanchez, D Luck, M Yli-Halla, H Muntau and Ph Quevauviller, European Commission, Brussels, 2001.

36. Report EUR 17554 EN, Ph. Quevauviller, G Rauret, J F Lopez-Sanchez, R Rubio, A M Ure and H Muntau, European Commission, Brussels, 1997.

37. M Biasioli, R Barberis and F Ajmone-Marsan, Sci. Total Environ., in press.

38. C Whalley, A Hursthouse, S Rowlatt, P Iqbal-Zahid, H Vaughan and R Durant, Water Air Soil Pollut., 112 (1999) 389.

39. E Ruiz-Cortes, R Reinoso, E Diaz-Barrientos and L Madrid, Environ. Geochem. Health, $27 \quad$ (2005) 465. 


\section{Legends for Figures}

Figure 1 Analyte fractionation patterns and recoveries with respect to equivalent pseudototal PTE concentrations obtained when three different laboratories sequentially extracted the same urban soil. Results presented are averages over replicate extractions: GLA (Glasgow, $\mathrm{n}=7$ ); LJU (Ljubljana, $\mathrm{n}=4$ ); SEV (Sevilla, $n=4)$. LJU did not measure iron concentration.

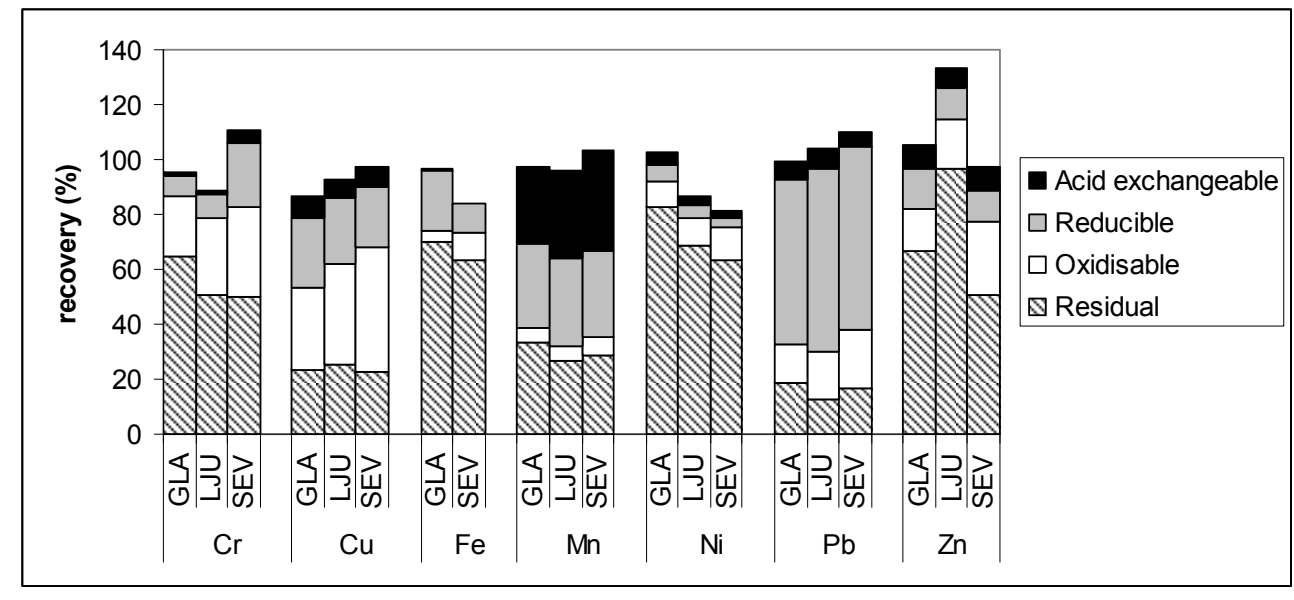




\begin{tabular}{|c|c|c|}
\hline 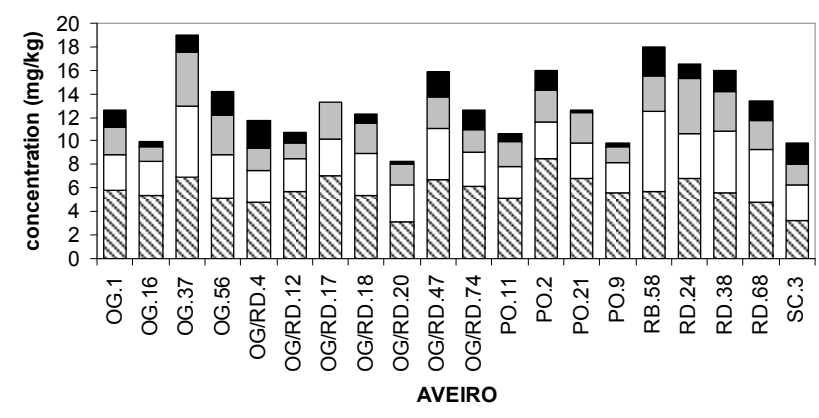 & 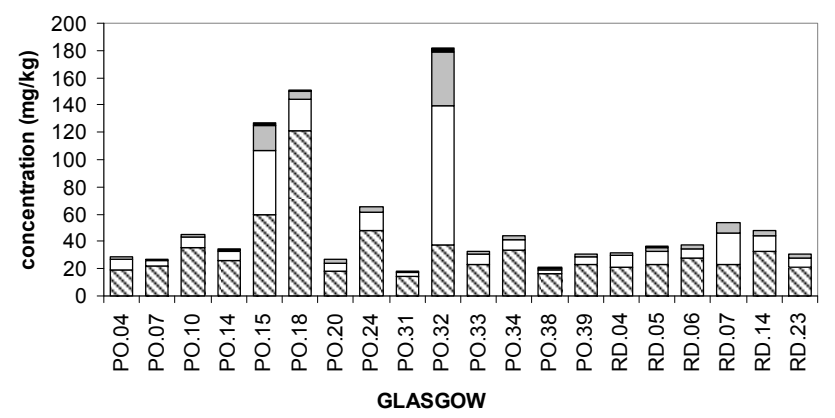 & 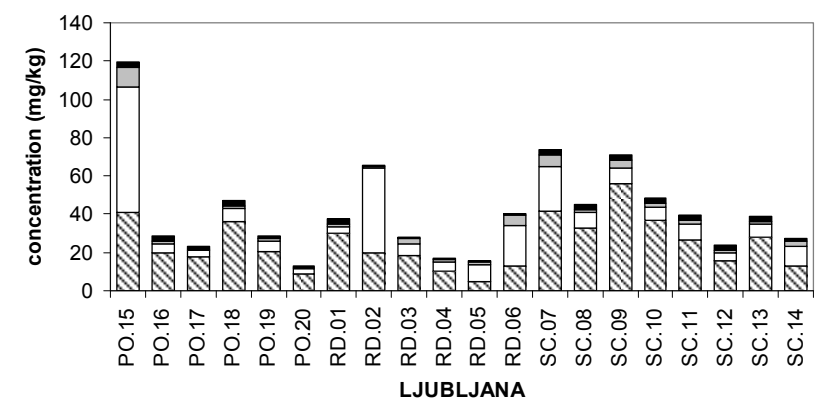 \\
\hline 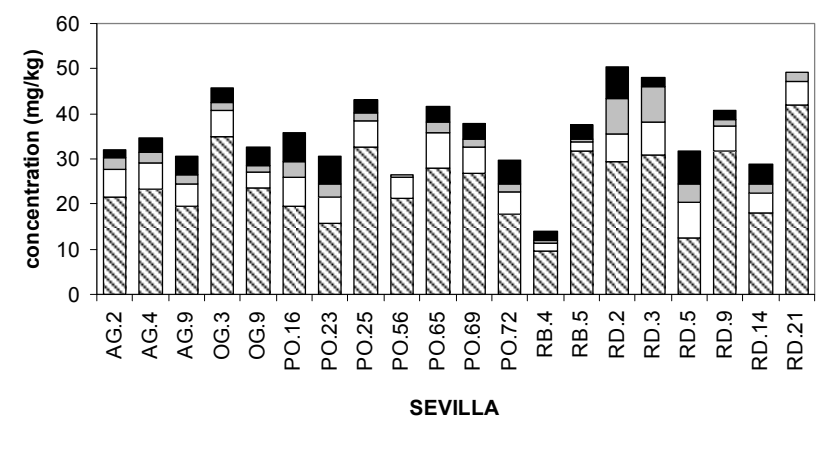 & 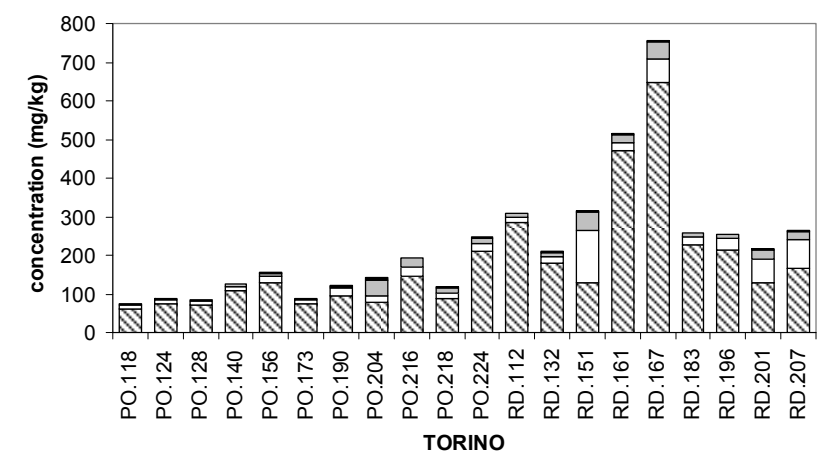 & $\begin{array}{ll}\text { KEY: } & \begin{array}{l}\text { Acid exchangeable } \\
\text { Reducible } \\
\text { Oxidisable } \\
\text { Residual }\end{array} \\
\mathrm{AG}=\text { Agricultural } & \mathrm{PO}=\text { Parks/open spaces } \\
\mathrm{OG}=\text { Ornamental gardens } & \mathrm{RD}=\text { Roadsides } \\
\mathrm{RB}=\text { Riverbanks } & \mathrm{SC}=\text { School playgrounds }\end{array}$ \\
\hline
\end{tabular}


Figure 3.

Fractionation of copper in urban soils by means of the BCR sequential extraction (results for soil AVE OG/RD.17 plotted at $1 / 10^{\text {th }}$ actual concentrations).

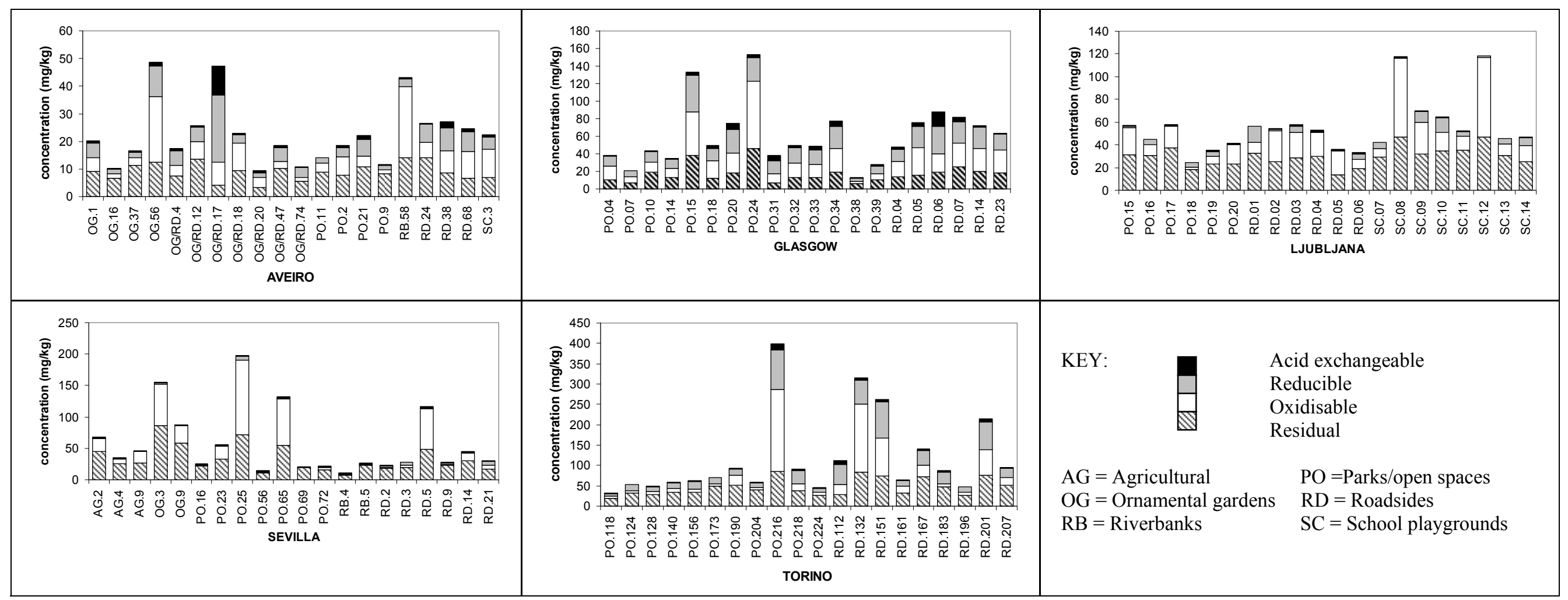


Figure 4. Fractionation of iron in urban soils by means of the BCR sequential extraction.

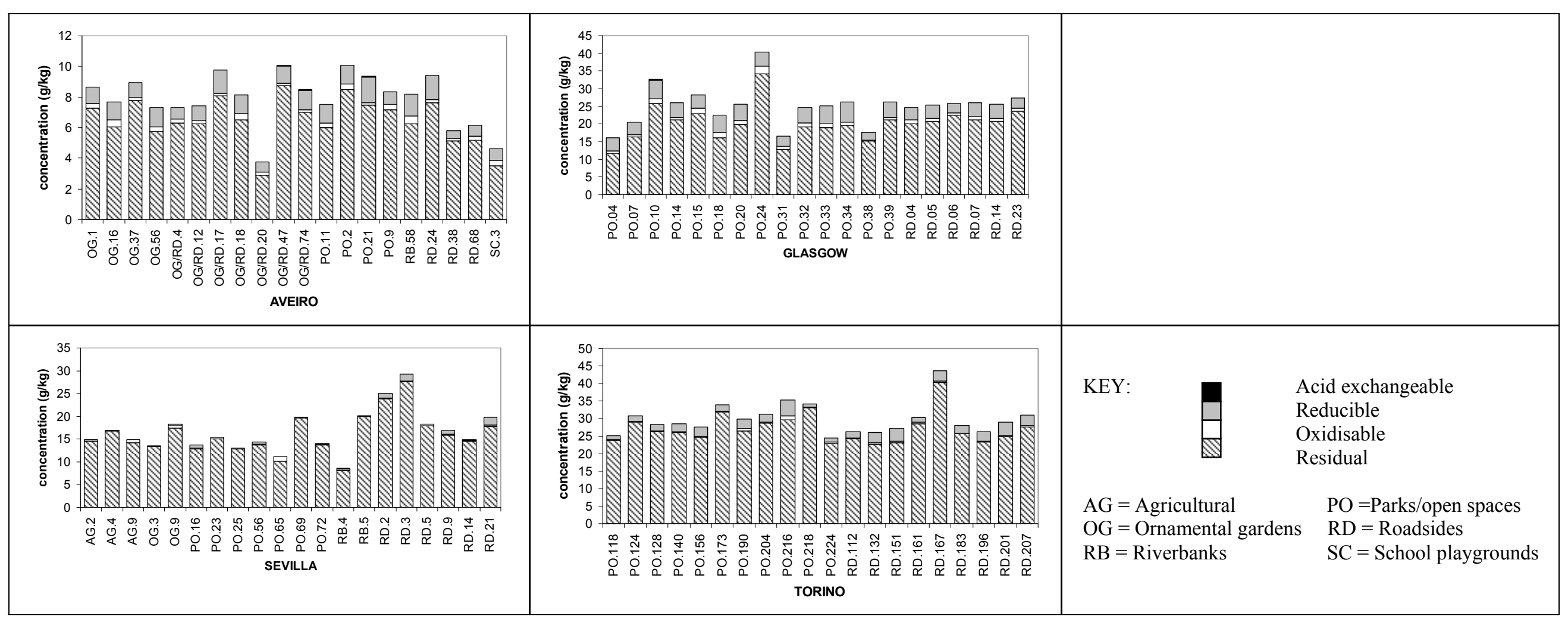




\begin{tabular}{|c|c|c|}
\hline 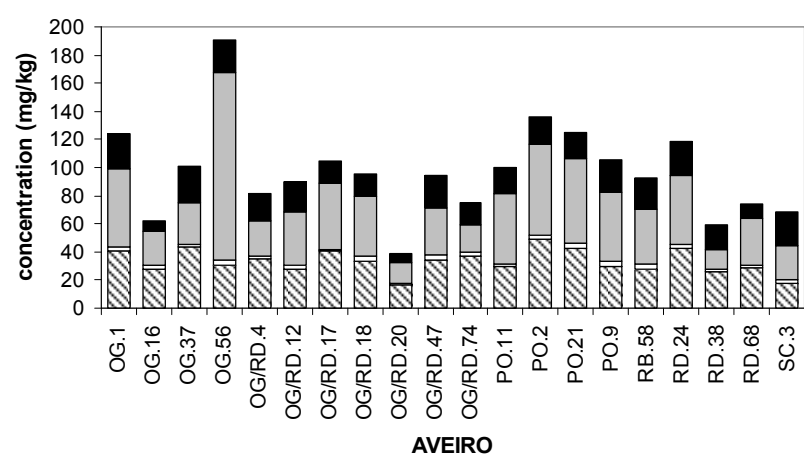 & 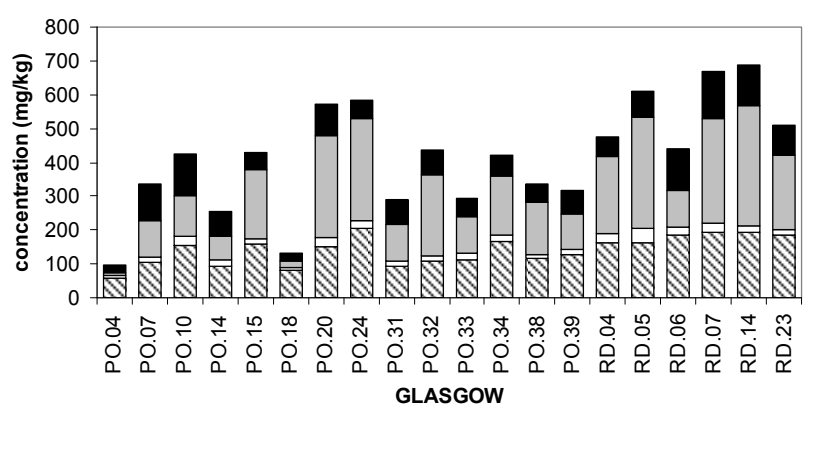 & 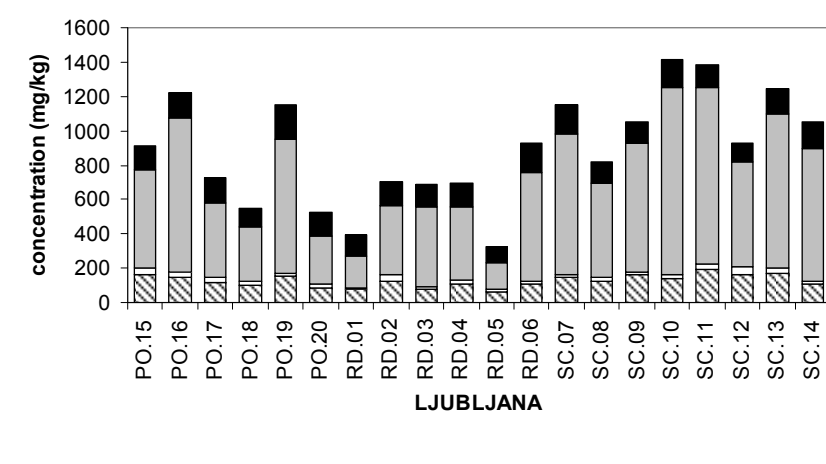 \\
\hline 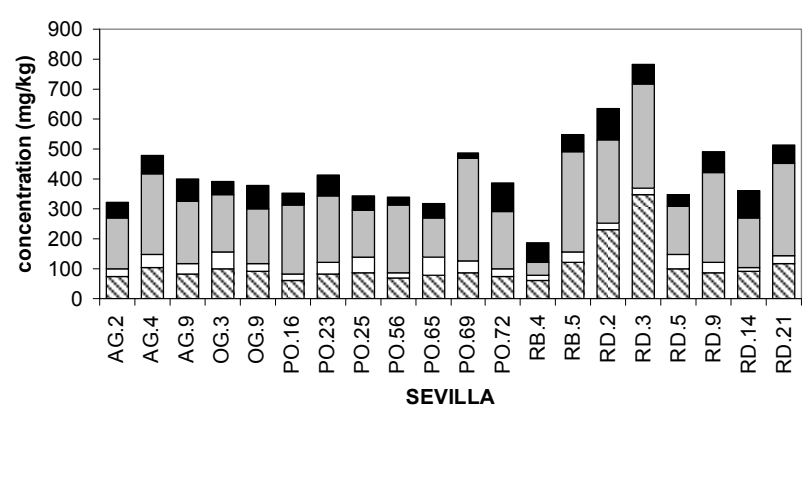 & 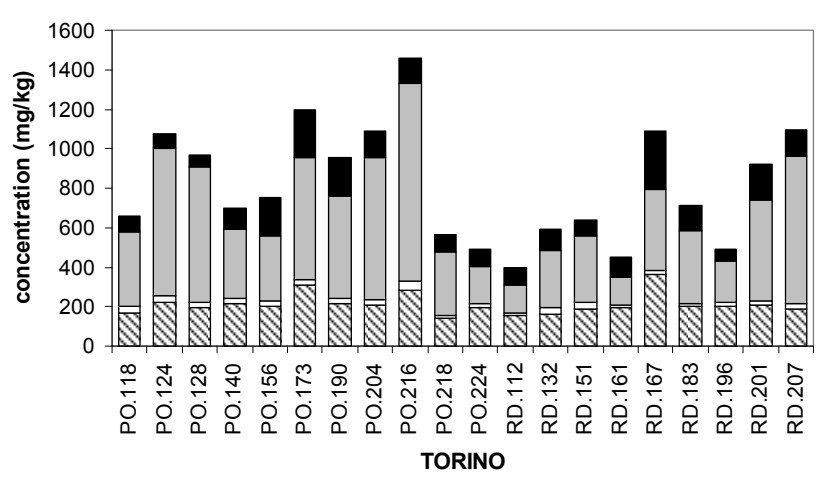 & $\begin{array}{ll}\text { KEY: } & \begin{array}{l}\text { Acid exchangeable } \\
\text { Reducible } \\
\text { Oxidisable } \\
\text { Residual }\end{array} \\
\mathrm{AG}=\text { Agricultural } & \mathrm{PO}=\text { = Parks/open spaces } \\
\mathrm{OG}=\text { Ornamental gardens } & \mathrm{RD}=\text { Roadsides } \\
\mathrm{RB}=\text { Riverbanks } & \mathrm{SC}=\text { School playgrounds }\end{array}$ \\
\hline
\end{tabular}




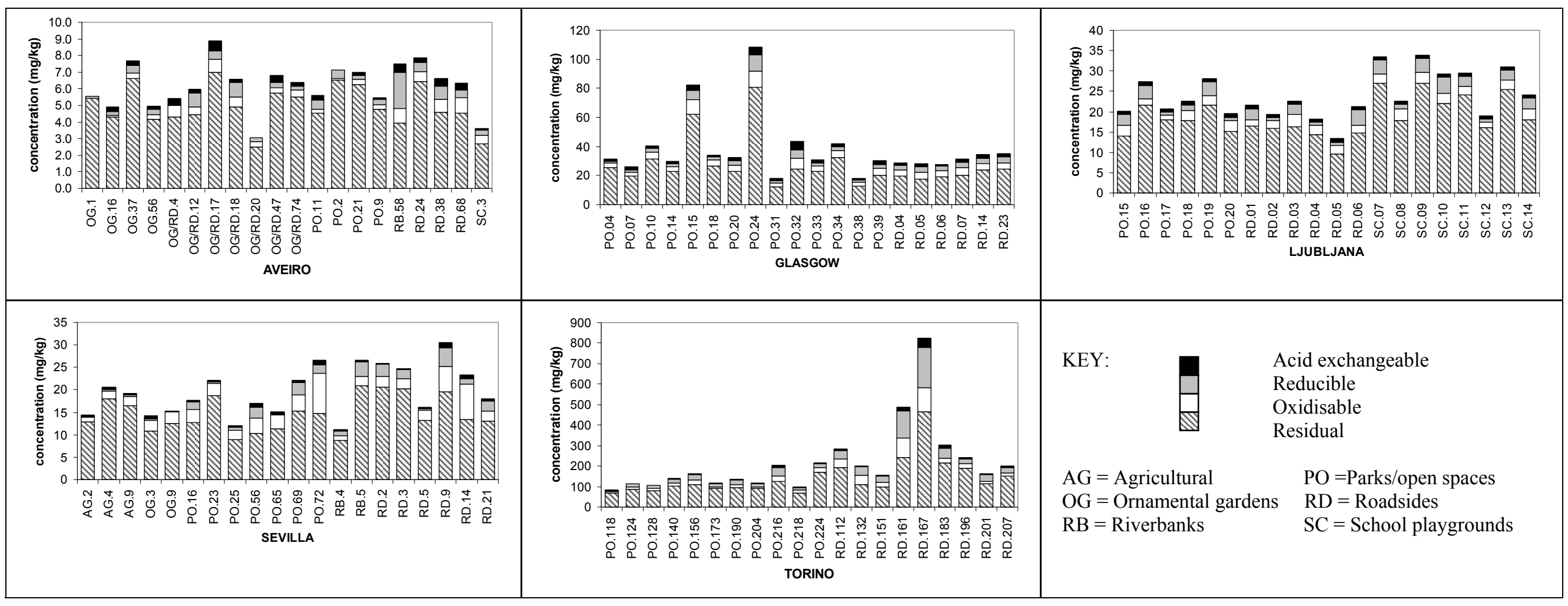




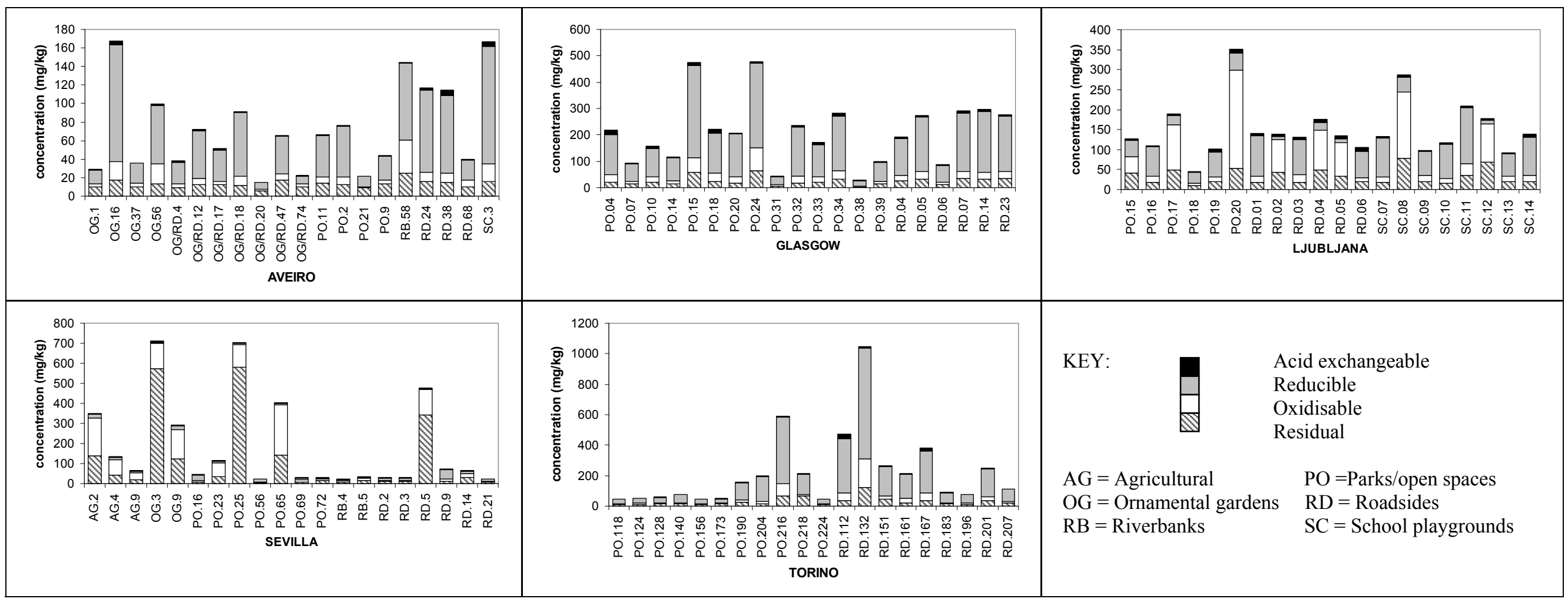




\begin{tabular}{|c|c|c|}
\hline 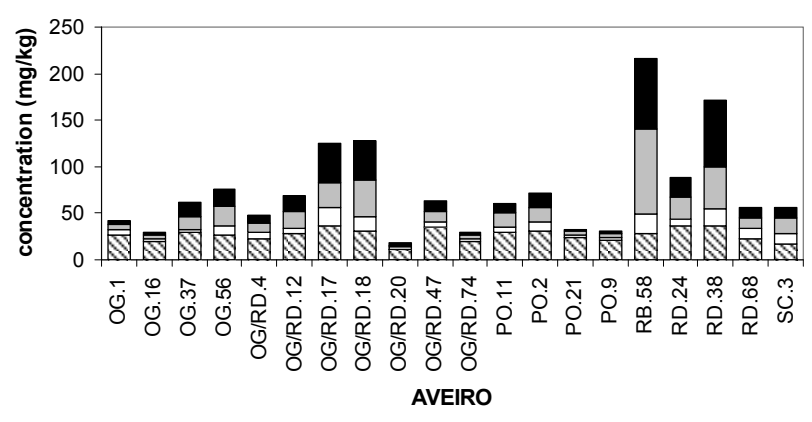 & 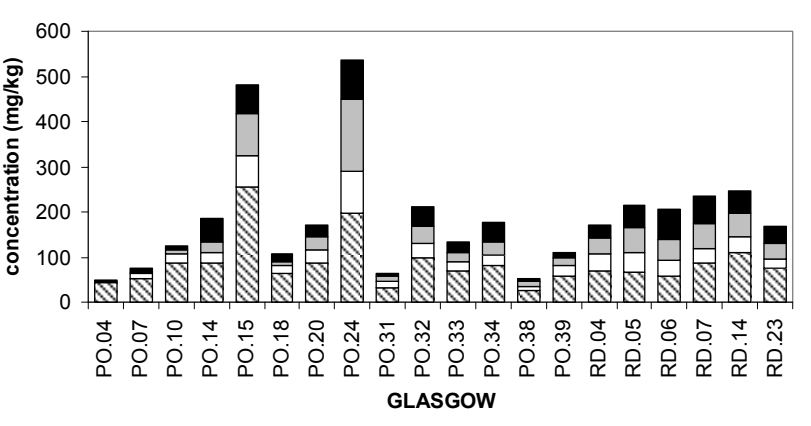 & 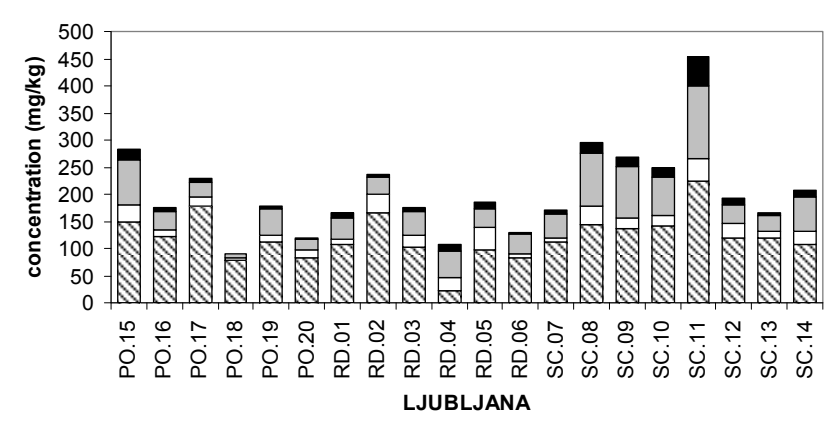 \\
\hline 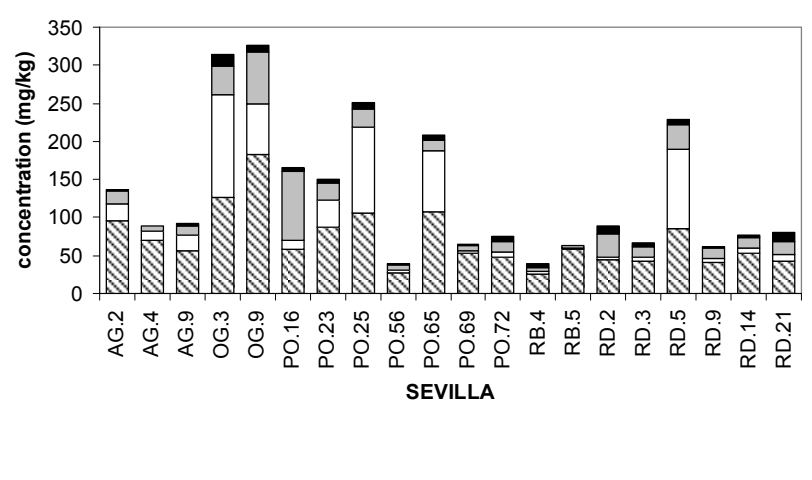 & 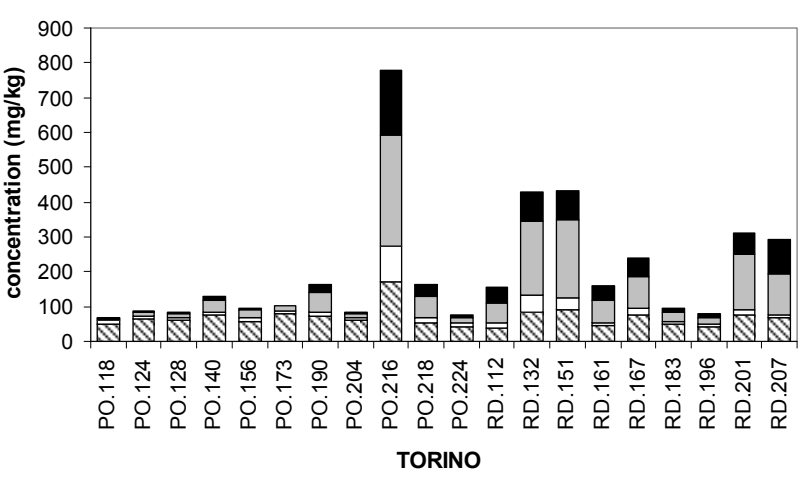 & $\begin{array}{ll}\text { KEY: } & \begin{array}{l}\text { Acid exchangeable } \\
\text { Reducible } \\
\text { Oxidisable } \\
\text { Residual }\end{array} \\
\mathrm{AG}=\text { Agricultural } & \mathrm{PO}=\text { =arks/open spaces } \\
\mathrm{OG}=\text { Ornamental gardens } & \mathrm{RD}=\text { Roadsides } \\
\mathrm{RB}=\text { Riverbanks } & \mathrm{SC}=\text { School playgrounds }\end{array}$ \\
\hline
\end{tabular}


Table 1. Details of apparatus and reagents used by project partners involved in sequential extraction of urban soil samples

\begin{tabular}{|c|c|c|c|c|c|c|}
\hline & $\begin{array}{l}\text { Shaker } \\
\text { (Type, } \\
\text { model and } \\
\text { speed) }\end{array}$ & $\begin{array}{l}\text { Centrifuge } \\
\text { (Model } \\
\text { and } \\
\text { conditions) }\end{array}$ & $\begin{array}{l}\text { Microwave- } \\
\text { assisted } \\
\text { digestion } \\
\text { (Model and } \\
\text { conditions) }\end{array}$ & $\begin{array}{l}\text { PTE } \\
\text { measurement } \\
\text { (Technique and } \\
\text { instrument) }\end{array}$ & Calibration & Reagents (grade and supplier) \\
\hline Ljubljana & $\begin{array}{l}\text { Orbital } \\
\text { shaker } \\
\text { (Yellow } \\
\text { Line OS } 2 \\
\text { basic) } 550 \\
\text { rpm }\end{array}$ & $\begin{array}{l}\text { Hettich, } \\
\text { Rotanta } 96 \\
\text { S, } 3000 \mathrm{~g}, \\
20 \mathrm{~min}\end{array}$ & $\begin{array}{l}\text { CEM, MDS- } \\
2000, \\
1 \text { g soil : } 20 \mathrm{ml} \\
\text { acid }\end{array}$ & $\begin{array}{l}\text { FAAS } \\
\text { (PerkinElmer } \\
1100 B) / \\
\text { ETAAS } \\
\text { (PerkinElmer } \\
\text { Zeeman 5100) }\end{array}$ & $\begin{array}{l}\text { Single element standards } \\
\text { prepared from } \\
\text { commercial solutions } \\
\text { (Merck) }\end{array}$ & $\begin{array}{l}\text { Nitric acid, hydrochloric acid, acetic acid, } \\
\text { ammonium acetate and hydrogen peroxide (all For } \\
\text { Analysis grade) from Merck. } \\
\text { Hydroxylammonium chloride (PA) from Fluka } \\
\text { Chimica }\end{array}$ \\
\hline Sevilla & $\begin{array}{l}\text { Orbital } \\
\text { shaker } \\
\text { (New } \\
\text { Brunswick) } \\
200 \text { rpm } \\
\end{array}$ & $\begin{array}{l}\text { Backman } \\
\text { Coulter, } \\
3000 \mathrm{~g}, \\
10 \mathrm{~min}\end{array}$ & $\begin{array}{l}\text { Milestone } \\
\text { Ethos } 900, \\
0.5 \mathrm{~g} \text { soil : } 10 \\
\mathrm{ml} \text { acid }\end{array}$ & $\begin{array}{l}\text { ICPOES } \\
\text { (Thermo Jarrell } \\
\text { Ash IRIS } \\
\text { Advantage) }\end{array}$ & $\begin{array}{l}\text { Multi-element reagent- } \\
\text { matched standards } \\
\text { prepared from single- } \\
\text { element commercial } \\
\text { solutions (Merck) }\end{array}$ & All reagent AR grade from Merck \\
\hline
\end{tabular}


Table 2. Results obtained for analysis of reference soils certified for extractable PTE contents $\left(\mathrm{mg} \mathrm{kg}^{-1}\right)$

\begin{tabular}{|c|c|c|c|c|c|c|c|c|}
\hline CRM & & & Replicates & $\mathrm{Cr}$ & $\mathrm{Cu}$ & $\mathrm{Ni}$ & $\mathrm{Pb}$ & $\mathrm{Zn}$ \\
\hline BCR 601 & Step 1 & Indicative & & $0.35 \pm 0.08$ & $10.5 \pm 0.8$ & $7.82 \pm 0.84$ & $2.28 \pm 0.44$ & $261 \pm 13$ \\
\hline \multirow[t]{7}{*}[34]{} & & GLA & 7 & $0.33 \pm 0.10$ & $10.8 \pm 2.1$ & $6.66 \pm 0.98$ & $1.57 \pm 0.82$ & $240 \pm 34$ \\
\hline & Step 2 & Indicative & & $10.6 \pm 0.9$ & $72.8 \pm 4.9$ & $10.6 \pm 1.2$ & $205 \pm 11$ & $266 \pm 17$ \\
\hline & & GLA & 7 & $10.0 \pm 0.6$ & $68.9 \pm 7.5$ & $10.9 \pm 0.4$ & $208 \pm 11$ & $266 \pm 16$ \\
\hline & Step 3 & Indicative & & $14.4 \pm 2.6$ & $78.6 \pm 8.9$ & $6.04 \pm 1.27$ & $19.7 \pm 5.8$ & $106 \pm 11$ \\
\hline & & GLA & 7 & $11.9 \pm 0.2$ & $65.3 \pm 5.0$ & $6.68 \pm 0.24$ & $16.9 \pm 3.1$ & $106 \pm 5$ \\
\hline & Step 4 & Indicative & & $78.2 \pm 6.5$ & $60.4 \pm 4.9$ & $50.5 \pm 4.3$ & $38.0 \pm 8.7$ & $161 \pm 14$ \\
\hline & & GLA & 7 & $85.0 \pm 2.7$ & $59.7 \pm 1.7$ & $54.0 \pm 2.9$ & $40.0 \pm 4.4$ & $169 \pm 4$ \\
\hline BCR 701 & Step 1 & Certified & & $2.26 \pm 0.28$ & $49.3 \pm 3.0$ & $15.4 \pm 1.6$ & $3.18 \pm 0.37$ & $205 \pm 10$ \\
\hline \multirow[t]{11}{*}[35]{} & & LJU & 3 & $2.10 \pm 0.30$ & $31.8 \pm 1.5$ & $15.9 \pm 2.4$ & $3.10 \pm 0.20$ & $154 \pm 15$ \\
\hline & & $\mathrm{SEV}$ & 6 & $2.32 \pm 0.40$ & $39.4 \pm 7.0$ & $11.9 \pm 1.9$ & $2.78 \pm 0.63$ & $162 \pm 24$ \\
\hline & Step 2 & Certified & & $45.7 \pm 3.1$ & $124 \pm 6$ & $26.6 \pm 2.0$ & $126 \pm 5$ & $114 \pm 8$ \\
\hline & & LJU & 3 & $44.8 \pm 1.4$ & $96.9 \pm 5.2$ & $21.9 \pm 1.9$ & $108 \pm 4$ & $119 \pm 6$ \\
\hline & & SEV & 6 & $45.9 \pm 8.8$ & $103 \pm 2$ & $20.7 \pm 0.7$ & $102 \pm 4$ & $115 \pm 9$ \\
\hline & Step 3 & Certified & & $143 \pm 12$ & $55.2 \pm 6.1$ & $15.3 \pm 1.5$ & $9.28 \pm 3.03$ & $45.7 \pm 5.1$ \\
\hline & & LJU & 3 & $150 \pm 8$ & $80.2 \pm 7.5$ & $14.4 \pm 1.3$ & $10.5 \pm 1.3$ & $44.9 \pm 4.6$ \\
\hline & & $\mathrm{SEV}$ & 6 & $148 \pm 8$ & $74.8 \pm 3.7$ & $17.1 \pm 2.0$ & $10.2 \pm 1.7$ & $61.4 \pm 10.0$ \\
\hline & Step 4 & Indicative & & $62.5 \pm 7.4$ & $38.5 \pm 11.2$ & $41.4 \pm 4.0$ & $11.0 \pm 5.2$ & $95 \pm 13$ \\
\hline & & LJU & 3 & $64.5 \pm 5.4$ & $40.3 \pm 3.6$ & $45.8 \pm 2.9$ & $18.2 \pm 2.1$ & $104 \pm 6$ \\
\hline & & SEV & 6 & $49.2 \pm 6.0$ & $31.2 \pm 8.0$ & $30.0 \pm 2.8$ & $15.2 \pm 2.3$ & $80.3 \pm 9.8$ \\
\hline
\end{tabular}

Results presented are mean values \pm one standard deviation for the number of replicates specified; GLA indicates results obtained by Team Glasgow (Strathclyde/Paisley); LJU results obtained in Ljubljana; SEV results obtained in Sevilla 
Table 3. Results obtained for analysis of Glasgow urban soil (pseudototal analyte concentration in $\mathrm{mg} \mathrm{kg}^{-1}$ ).

\begin{tabular}{|l|l|l|l|l|l|l|l|l|}
\hline & Replicates & $\mathrm{Cr}$ & $\mathrm{Cu}$ & $\mathrm{Fe}(\%)$ & $\mathrm{Mn}$ & $\mathrm{Ni}$ & $\mathrm{Pb}$ & $\mathrm{Zn}$ \\
\hline Glasgow & 34 & $43.2 \pm 3.0$ & $111 \pm 5$ & $3.06 \pm 0.12$ & $442 \pm 18$ & $48.8 \pm 7.0$ & $389 \pm 25$ & $177 \pm 11$ \\
\hline Ljubljana & 5 & $48.5 \pm 0.6$ & $133 \pm 1$ & $\mathrm{NA}$ & $487 \pm 6$ & $57.0 \pm 0.8$ & $439 \pm 3$ & $180 \pm 7$ \\
\hline Sevilla & 6 & $37.2 \pm 1.1$ & $108 \pm 2$ & $2.76 \pm 0.42$ & $369 \pm 6$ & $50.5 \pm 1.3$ & $343 \pm 7$ & $151 \pm 2$ \\
\hline
\end{tabular}

Results presented are mean values \pm one standard deviation for the number of replicates specified 